\title{
THE EFFECT OF TRENCHING ON THE SPREAD OF YELLOW LAMINATED ROOT ROT OF DOUGLAS FIR ${ }^{1}$
}

\author{
By G. W. WALLIS ${ }^{2}$ and D. C. BUCKLAND ${ }^{3}$
}

Born in Lloydminster. Sask., 1925, B.S.F. 1951 (Brit. Col.) Undergraduate experience in forest pathology. Service with the Canadian Navy 19431946. Joined the staff of the Forest Biology Division in 1951 to study decay in British Columbia. At present engaged in a study of root rot of Douglas fir.

In 1931 a small patch of 15- to 20-year-old Douglas fir at the Cowichan Lake Forest Experiment Station, Vancouver Island, was observed dying from root rot, subsequently determined to be caused by Poria weirii Murr, or a form of it ". Two trenches were dug to observe their influence on the spread of the disease. The first trench encircled the affected area, enclosing approximately 0.1 acres, and the second trench formed an isolation zone around the first, enclosing an additional 0.3 acres (Fig. 1) ${ }^{\circ}$. These trenches were one foot wide and down to hardpan, approximately 18 inches. Root rot was not observed in the isolation zone at the time the experiment was established. Periodic examinations of the plot were made between 1931 and 1951. In 1952 a thinning project in the area interfered with the natural stand conditions so that the experiment as originally outlined was concluded.

The condition of the trees in the inner plot at the time of each examination is summarized in Table 1. The number of trees was reduced from 174 in 1931 to 68 in 1951 , or a loss of $61 \%$ of the original stand. Ninety-nine of the 174 trees were dominant or codominant and 75 were intermediate or suppressed; 49 , or $50 \%$, of the former and 23 , or $30 \%$, of the latter were killed by root rot. The average annual loss from root rot was $1.5 \%$ of the dominant and codominant trees, or $2.1 \%$ of all trees. Thirty-four trees, all intermediate or suppressed, died from suppression or unknown causes.

The gradual spread of the disease in the inner plot and the initiation of new centers of infection within the isolation zone are illustrated in Figs. 2 to 4. The disease in the inner plot had spread to the trench more than ten years prior to the final examination, at which time it had not crossed into the isolation zone. Centers of infection which have arisen within the isolation zone (Fig. 1) are separated from the infected trees in the inner plot by many healthy trees. It is apparent that the trench has prevented the root spread of the disease into the outer plot.

This experiment indicares that properly-maintained trenches around centers of infection provide a control for the spread of the disease through the roots.

\footnotetext{
${ }^{1}$ Contribution No. 179, Forest Biology Division, Science Service, Department of Agriculture, Ottawa, Canada.

${ }^{2}$ Agricultural Research Officer, Forest Biology Laboratory, Victoria, B. C

${ }^{3}$ Associate Professor of Forest Pathology, University of British Columbia, Vancouver, B.C. Received for publication April 1, 1955.

'Mounce, I., Bier, J. E., and Nobles, M. K. A root-rot of Douglas fir caused by Poria weirij. Can. J. Research C, 18: 522-533. 1940.

${ }^{5}$ British Columbia Forest Service Experimental Plot 193B. Established in 1931 by J. D. Curtis and S. R. Schenstrom.
} 
DECEMBER, 1955

TABLE 1

The Number and Mortality of Trees Occurring on Experimental Plot 193B, Cowichan Lake, British Columbia

\begin{tabular}{|c|c|c|c|c|c|}
\hline \multirow[t]{2}{*}{ Period } & \multirow{2}{*}{$\begin{array}{l}\text { Tree } \\
\text { class }\end{array}$} & \multirow{2}{*}{$\begin{array}{l}\text { No. of trees } \\
\text { living }\end{array}$} & \multicolumn{3}{|c|}{ No. of trees killed } \\
\hline & & & Root rot & Other causes & Total \\
\hline TO & $D \& C$ & 99 & & & \\
\hline \multirow{2}{*}{1931} & $I \& S$ & 75 & & & \\
\hline & Total & 174 & & & \\
\hline 1931- & $\mathrm{D} \& \mathrm{C}$ & 78 & 21 & - & 21 \\
\hline \multirow[t]{2}{*}{1935} & $I \& S$ & 50 & 9 & 16 & 25 \\
\hline & Total & 128 & 30 & 16 & 46 \\
\hline $1936-$ & D \& C & 67 & 11 & - & 11 \\
\hline \multirow[t]{2}{*}{1940} & I \& S & 41 & 6 & 3 & 9 \\
\hline & Total & 108 & 17 & 3 & 20 \\
\hline 1941- & $D \& C$ & 56 & 11 & - & 11 \\
\hline \multirow[t]{2}{*}{1945} & $I \& S$ & 26 & 5 & 10 & 15 \\
\hline & Total & 82 & 16 & 10 & 26 \\
\hline $1946-$ & D \& C & 50 & 6 & - & 6 \\
\hline \multirow[t]{2}{*}{1951} & $I \& S$ & 18 & 3 & 5 & 8 \\
\hline & Total & 68 & 9 & 5 & 14 \\
\hline \multirow[t]{3}{*}{1951} & D \& C & 50 & 49 & - & 49 \\
\hline & I \& S & 18 & 23 & 34 & 57 \\
\hline & Total & 68 & 72 & 34 & 106 \\
\hline
\end{tabular}

${ }^{1} \mathrm{D}=$ dominant trees, $\mathrm{C}=$ codominant, $\mathrm{I}=$ intermediate, $\mathrm{S}=$ suppressed.

It is unfortunate, however, that trenching is not economically feasible. It is known that viable inoculum can exist in old roots, stumps, and blocks of wood from one rotation to another ${ }^{\circ}$. Further, there is the possibility of air-borne spores infecting stumps and dead trees with the causal fungus and later spreading into the roots. When rots of healthy trees come in contact with these sources of inoculum, new centers of infection will start. Thus, while centers may be infrequent in a stand at present, new centers may develop at any time (Fig. 1).

Previous studies of the disease ${ }^{\circ}$ have indicated that $P$. weirii is not capable of spreading through the soil. The trenching experiment gives further evidence to support these observations, as there has been sufficient soil and litter accumulated in the trench over the last decade to allow the fungus to pass beyond the barrier, if it were capable of doing so. The fungus usually spreads through the major root system of a tree, and in these instances spread from tree to tree is through contact points of these larger roots.

Currently the influence of certain silvicultural and management practices on the control of the disease is being tested by the Division of Forest Disease Research of the United States Forest Service, Portland, Oregon, and the Forest Biology Laboratory, Victoria, B.C., but to date no economically sound control plan has evolved.

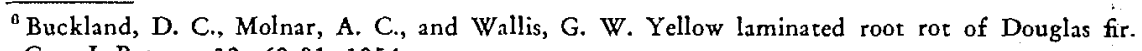
Can. J. Botany, 32: 69-81. 1954. 

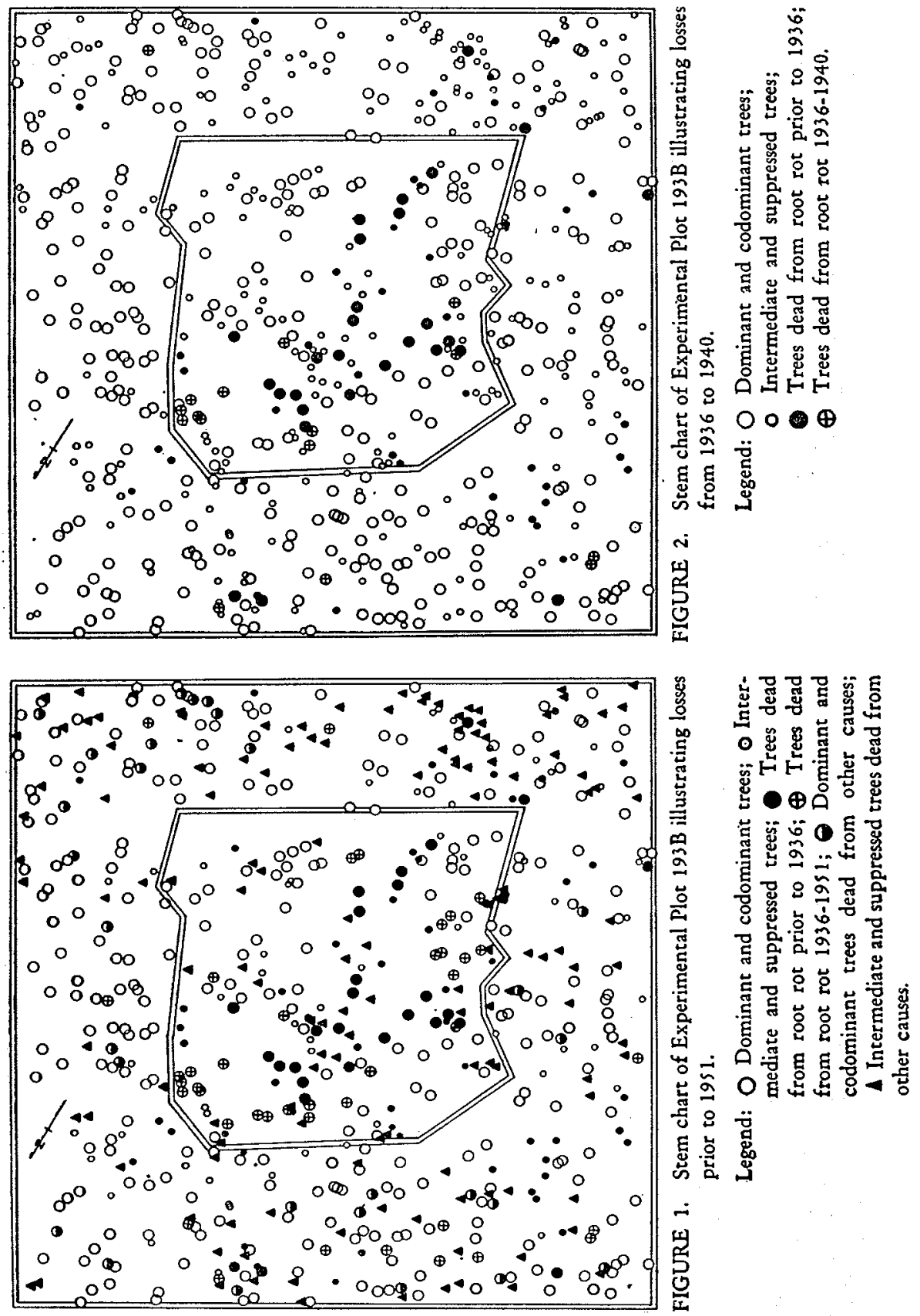

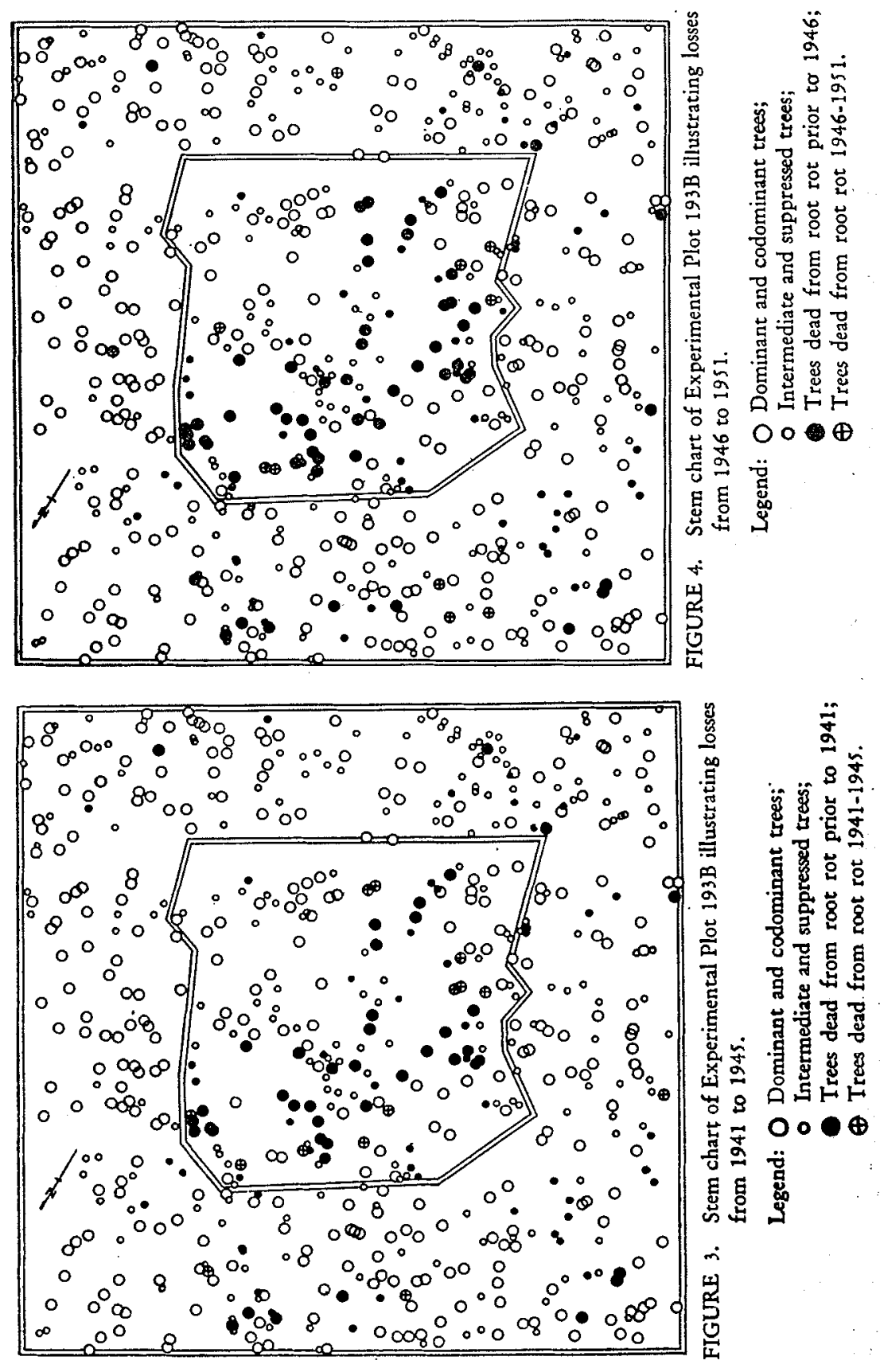